\title{
Gas Sensors for Early Detection of Fire Hazards caused by Vehicles in Underground Mines
}

\author{
Madeleine Martinsen ${ }^{1}$, Erik Dahlquist ${ }^{2 *}$, Anders Lönnermark ${ }^{3 *}$, Örjan Säker ${ }^{4 *}$ \\ ${ }^{1}$ ABB Industrial Automation, Industrial PhD student at MDH, Västerås Sweden \\ ${ }^{2} \mathrm{MDH}$, Mälardalens University MDH, Västerås Sweden \\ ${ }^{3}$ RISE, Swedish Research Institute, Borås Sweden \\ ${ }^{4}$ Epiroc, Rocktec Automation Epiroc Rock Drills AB, Örebro Sweden
}

\begin{abstract}
Sensors play a key role today and have been developed to be used in many applications that can be life critical as with e.g. fire alarms. When mines now start investing in information systems and information technology infrastructure, they have taken one step closer to digitization. This in turn creates opportunities for the mines to become completely autonomous in the future. Controlling, monitoring and planning such production requires new digitized solutions. Part of such a solution could for example be to mount different types of sensors in the mining process. Data gathering from sensors with diagnostics supported by predefined set-points enables early alarms allowing production personnel to react before a fire is a fact. This paper describes the conducted experimental study aiming at identifying risk for fire caused by mining vehicles in underground mines. The test result shows that some types of sensors have potential to early detect fire hazards.
\end{abstract}

Keywords: fire, underground mines, early diagnose, gas sensors, overheating, ventilation

\section{Introduction}

The Energy Revolution, Industry 4.0 and Electricity Mobility are focus areas that will affect the mining industry and how they will operate it in the future. Furthermore, it will transform and replace today's dirty and dangerous workactivities when for example. mining trucks is being powered by batteries.

In addition, it will support the development towards a fully autonomous mining solution. Such operation will require faster approaches to be able to detect changes in production and prevent something serious from occurring.
A challenging goal which the Swedish government has decided, is to become a fossil-free country in year 2045. The energy used for only ventilation in some mines represent $49 \%$ of their total energy consumption (Natural Resources, 2005). One percent of the total energy consumption in Sweden relates to ventilating the Swedish mines. This has led to that the mining industry now starts to explore how they can contribute to this goal.

One part of the solution that can support this goal is the replacement of the mining truck fleet from being dieselpowered to be powered by batteries. An example is the project that took place September 18th, 2018 in the world's most effective open-pit mine Aitik (Boliden) in Sweden. The goal of the project is to investigate whether it is possible to replace parts of Aitik's transport system with electrified trucks. Aiming at that the majority tons of rock that are being transported annually in the open-pit can be moved completely without fossil fuels.

The tested traveling distance (Figure 1) is approximately $700 \mathrm{~m}$ and is expected to save around $830 \mathrm{~m}^{3}$ of diesel per year. This gives Boliden the possibility to reduce greenhouse gas emissions by up to $80 \%$ on the routes where the technology can be implemented. Other positive results from the test in proved that the electrified truck was

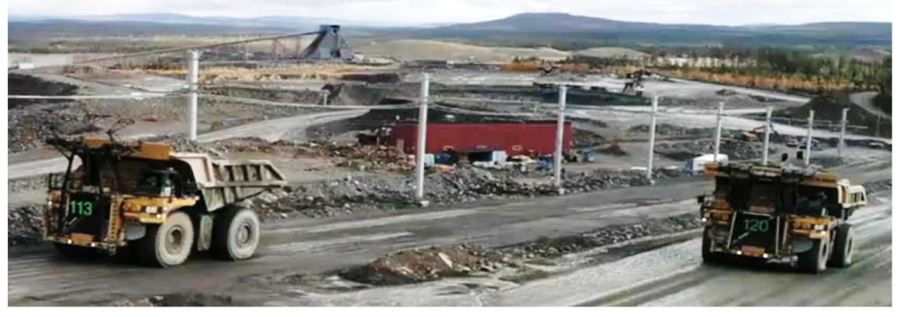

Figure 1. Boliden, Aitik electrified truck versus diesel truck race. 
Many advantages can be observed with this transition from diesel to battery-powered trucks, related to cost as for carbon dioxide reduction, resulting in cleaner and healthier working environment. However, the mining industry faces also challenges to ensure that productivity is maintained or improved further while preventing it from compromising safety at the workplace when introducing new mining vehicle fleets. New risks, issues and challenges with batterypowered trucks are:

- Fire and smoke development (Bøe and Reitan, 2018)

- Mitigation and fire suppression (Bøe and Reitan, 2018)

- Ventilation and evacuation (Ingasson et al., 2015)

- Released gases which are not only flammable but also toxic (Ingasson et al., 2015)

Commercial Li-ion cells contain substances that can release toxic fluorine gases such as hydrogen fluoride (HF) and other harmful gases if undergoing failures (Ahlberg Tidblad, 2018; Larsson et al., 2018). Additional challenges, firefighter's have indicated that they lack to some extent knowledge, proper clothing, training and extinguishing technique to handle fires involving Li-ion cells.

Safety issues relating to fully autonomous mines are topics being discussed when the Global Mining Group, GMG, invites the mining industry to seminars and workshops around the world today. Taken all the above into account, it is understandable that there is a great interest to early diagnose as for detection of these problems that can occur in mines to minimize production stop.

\section{Background}

Common risks that may occur in both an open pit mine and an underground mine (Reddy et al., 2016) are for example:

- Sink Holes

- Slope Failure

- Roof Collapses

- Floods

- Rock Bursts

- Fires

- Toxic Gases

For fully autonomous mining a robust early warning safety system ought to be able and monitor as for determine possible threats caused by the listed risks. In addition, the entities like personnel and assets (machinery \& vehicle) need to be safe-guarded. Further key parameter to monitor is the mine area to provide insight on landscape changes and presence of danger zones that need to be demarcated. According to ((Reddy et al., 2016), sensor network is
Fire objects in Swedish mines 2008-2012

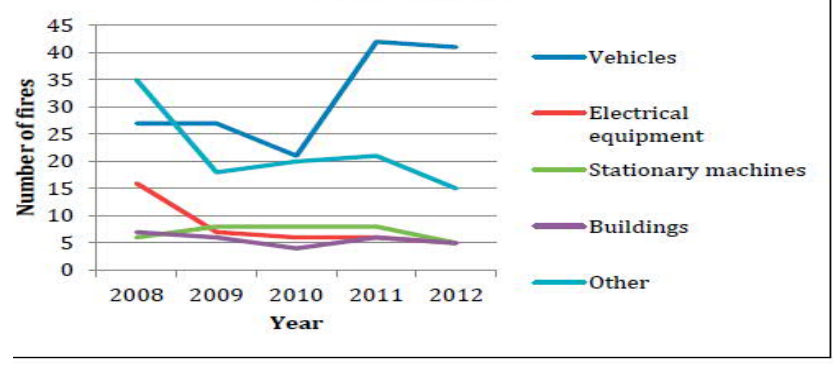

Figure 2. Fire objects in Swedish mines year 2008 - 2012.

recommended for early detection of hazards and their advantages have proven to be:

- Automated Measurement ability

- Ultra-low Power Consumption

- Versatility

- Cost-effectiveness

- Ease of manufacture

- Ease of deployment

Underground mining is hazardous and from a manufacturing system perspective challenging and unconventional. Developing an autonomous underground mining manufacturing system proves difficult due to inadequate connectivity and non-uniform manufacturing environment. Some mining businesses have or are investing in information systems (IS) and information technology (IT) to provide connectivity while others are somewhat reluctant and can be considered conservative when it comes to installing IS / IT solutions. Regarding the complexity of the manufacturing environment. It is a great challenge to automate the excavation using autonomous vehicles because the vehicles require many and advance sensors to discern the complex environment which further encumbers the network.

One of the most dangerous situations in an underground mining is fires. Especially those that are caused by mining vehicles. An overturned mining vehicle can produce a heat release rate (HRR) up to $200 \mathrm{MW}$ and a temperature above 1000 degrees C (Ingasson et al., 2015; Hansen, 2015). Such fires can cause rock movements so that part of the mine becomes unusable, and cause long production stops, until the rock wall has been secured again. Furthermore, it entails extensive remediation work and, in the worst case, fatal outcome.

Since year 2010 roughly one fire occurs per week in the Swedish mines. A great deal of the fires is caused by mining vehicles (GRAMKO annual report, 2013) (Figure 2). The number of reported fires due to mining vehicles per year has not changed significantly, since then. Just as many fires $2^{\text {occur today as then and it is a topic being discussed at }}$ 
Swemin's (the Swedish mining industry's industry organization) yearly meetings. A recurring comment from discussions with mine workers in Sweden, it's not a question whether it will start to burn or not but more about when and where.

Sweden has about 20 active mines, ore and metal production such as e.g. iron ore, copper, gold and silver, though no coal mines. Fires seem to occur evenly distributed in all active mines in Sweden. Fires in mines around the world are also dominantly caused by vehicles and mobile equipment, resulting in dangerous situations (Hansen, 2011; Hansen, 2018; Willstrand. 2018). This allows a strain on mining production with increased costs as a result, but not least the risk which miners are exposed to.

Most vehicle related fires in mines are caused by:

- Cables and hydraulic hoses (Ingasson et al., 2015)

- Fault and overheating of equipment, e.g. engines (Ingasson et al., 2015)

- Worn tires (Ingasson et al., 2015)

- Cable reel (Ingasson et al., 2015)

- Leakage of flammable liquids, that are sprayed onto hot surfaces (Hansen, 2015)

Today miners are trained to act as firefighters and start the extinguishing activity until the fire department arrives at the site. A complete autonomous mine will have none or fewer miners underground that will be able to support this activity. This in turn requires solutions that support smart inspections that will detect early changes in production before the situation develops into a dangerous state.

\section{Methodology}

\subsection{Introduction}

The basis for the study presented in this paper is a series of sensor experiments. The purpose of these experiments has been to evaluate the range of sensors, existing on the market today. The purpose of mounting sensors on mining vehicles is to detect the gases that arise before a fire is a fact on a mining vehicle. Gases can arise for example, from, overheated equipment that lead to plastic materials beginning to emit thermal decomposition products.

From early mining days, canary birds have been known for their ability to early detect toxic air and the purpose of this study is to verify the possibility of replacing them with IoT and sensor solutions. The requirements of the sensors must correspond to the sensitivity of the ability of a canary. When toxic air was detected in a mine shaft, the canary-bird stopped twittering. Which was the sign for the miners to start evacuating. Even worse if they saw the bird lying dead on the bottom of the bird cage, they knew that very little time was left to save themselves from meeting the same fate.

This describes the requirements on the sensors' requirements to be able and detect changes on the vehicle objects in an early phase and communicate that to an overall operation system (Beard and Carvel, 2005; Hansen, 2013). However, detecting emitting gases that develops a temperature around 100 degrees $\mathrm{C}$ and barely noticeable HRR demands sensors to be highly sensitive.

\subsection{Sensors}

The sensors used in the different test series measured the following parameters:

- Temperature

- Hydro carbons

- Carbon monoxide (CO)

- Carbon dioxide $\left(\mathrm{CO}_{2}\right)$

- Methane (CH4)

- Nitrogen dioxide $\left(\mathrm{NO}_{2}\right)$ concentrations

- and other NOx gases

- Relative humidity

- Air flow

The sensors were mounted on a frame construction (Figure 3 and 4) with wheels. In this way it was possible to change positions of the sensors relative to the emitting source (toxic gas). This allowed that it was possible to observe the distance when the sensors reacted as for the time it took for it to react. The setup of the lab equipment allowed the angle of the tested sensors to be varied and thereby it was possible to simulate inclines of e.g. a mine road. In addition, a fan was mounted to test how the sensors reacted to ventilation.

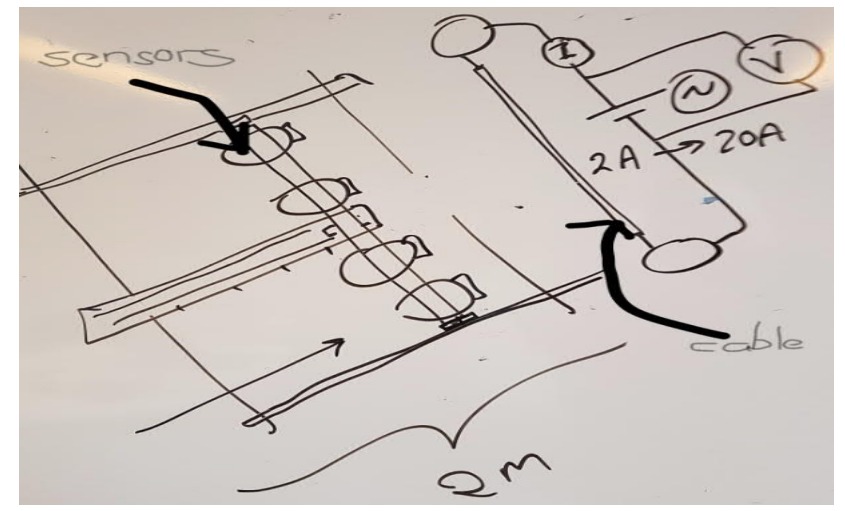

Figure 3. Test Equipment arrangement 


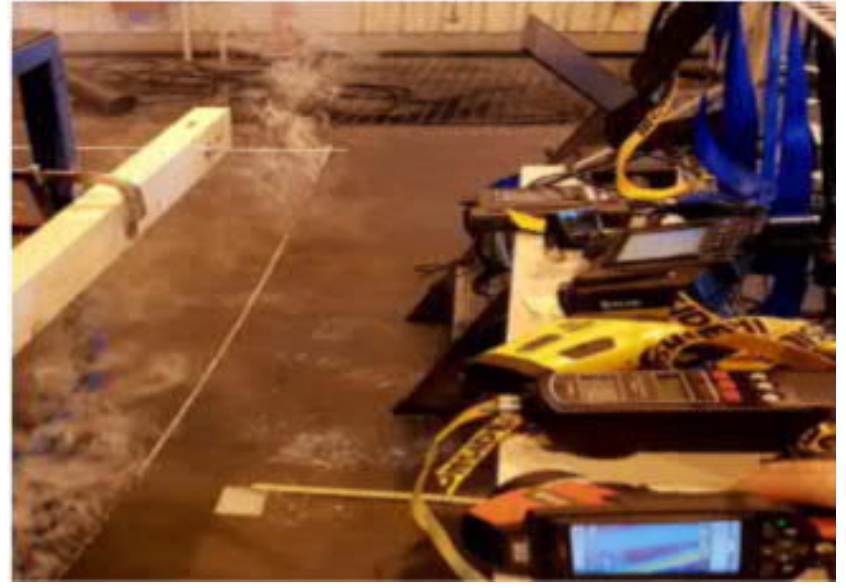

Figure 4. The test equipment at RISE Fire lab facility.

\subsection{Test sites}

Some tests were conducted at RISE Fire lab facilities (SP Brandteknik) in Borås, Sweden. The first tests were to verify if any sensors were able to detect the gases emitting from the cables and to observe at what distance. While second test, ventilation from the fan was included to disturb the sensors in the test cases. In addition, the fan was also used for sucking the gases to the sensors. Finally, disturbance from humidity was simulated with water boilers. Concluding test was conducted at Epiroc in Örebro, Sweden, in their machine hall.

In addition to those tests follow up tests were performed at Mälardalens University, Västerås in Sweden, chemistry lab. A couple of follow up tests were performed to verify the tests results as for further analyses.

The tests were divided into the following categories:

- Stress tests, detection capability. The initial test was to observe the sensors' capability reacting on the emitting gases.

- Sensitivity, distance to emitting source. Sensitivity test was to determine on what distances the sensors reacted on the emissions from the heated cables and the oil mist, respectively.

- Disturbance influenced by other sources. The sensors in mining environment need to be able to distinguish between normal mining air or if fire is about to evolve due to e.g. soot, oil mist (hole in hoses).

- Logging capability of the sensors, as in communication protocols. Logging of data from sensors will be essential as for communicating it to an on-line control system.
- Gas concentration, balloon tests. To determine and understand the amount of gases needed for the sensors to react.

\subsection{Test objects - Cables}

Emitting sources, more than ten different cable types, normally used on Epiroc mining vehicles were tested. The cables on a mining vehicle can be everything from $0.5 \mathrm{~m}$ up to $15 \mathrm{~m}$ long. The material of the cables varies and in the tests the following could be observed:

- Polyvinyl chloride (PVC)

- Polyethylene (PE)

- $\quad$ Polyurethane (PUR)

- Halogen free

These can emit e.g. hydrocarbons, cyanides, hydrochloric acid, etc., which have effects of quite different kinds. PVC provides hydrochloric acid, which can be harmful mainly for equipment. Cyanides are acute toxic to humans. Hydrocarbons can cause long-term injuries, type of respiratory problems and, in the worst case, cancer.

\section{Results from the experiments}

From the tests it can be determined that it is possible to detect the risk of emerging fire at an early stage with some of the sensors. However, it was observed that the sensors need to be close to the flue gas evolution between $0,5 \mathrm{~m}$ or less. Some sensors proved to be too insensitive to use directly, however some sensors could be used if gas could in some way could be sucked in to the detector. The conducted tests showed that a combination of sensors will be required to be able and detect the different gases, sources or heat development on mine vehicles in an early and efficient way.

The experiments were made by heating different cables by imposing a voltage and current to the cables (shown in Figure 3 and 4). The temperature of the actual cables was measured, the temperature from remote using Flir-camera and with two Photo ionization (PID)- instruments measuring VOC (volatile organic carbons). One VOC instrument is RAE MultiRae 3000. The other FotoVac (an older instrument).

During tests 2 at RISE in Borås, there were six experiments and peaks could be noted at 30, 50, 70, 100, 130- and 155-time units. The first cable that was tested was halogen free thermoplastic polyester. The second PVC with PUR coating. The third had two layers PVC. The fourth PE with PUR surrounding. The fifth only PVC and the sixth also only PVC. The first cable is $1.5 \mathrm{~mm} 2$ and voltage $2.2 \mathrm{~V}$ and current $50 \mathrm{~A}$ from start. At $58 \mathrm{~A}$ and $2.5 \mathrm{~V}$ we get first visible fume, but clearer fume at $4.1 \mathrm{~V}$ and $70 \mathrm{~A}$, when also the 
VOC sensors give clear signals, 2.4 respectively $38 \mathrm{mg} / \mathrm{l}$ for FotoVac respectively RAE MultiRae 3000.

It was noted that the peaks follow each other, and that Flir-camera gives a very good response in relation to the cable temperature. The PID meter from RAE gives a reasonably high response, while the older FotoVac has a smaller response, but still a clear response.

The clear response for VOC starts when the cables are fuming (see Figure 5, 6, 7 and 8). When the distance was 2 meters, no response was noted however at a distance from $0.2 \mathrm{~m}$ and less a clear response was observed. This is when there is a fan moving the smoke towards the sensors, but at the same time there is the normal ventilation sucking the air to the right, parallel to the cable away from the sensors. This showed that we need to have fans sucking air into the sensors, and this was later tested on Epiroc's vehicles in their machine test hall in Örebro.

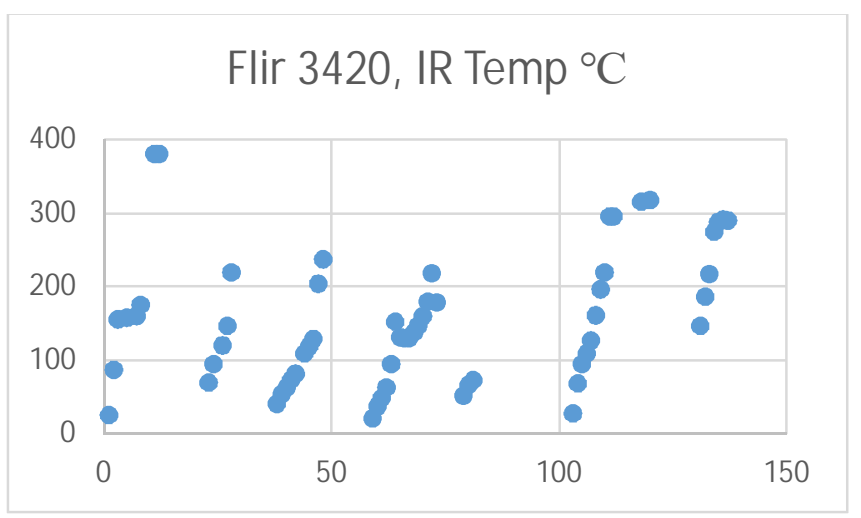

Figure 5 Peak results, sensor: Flir 3420, IR, Temperature

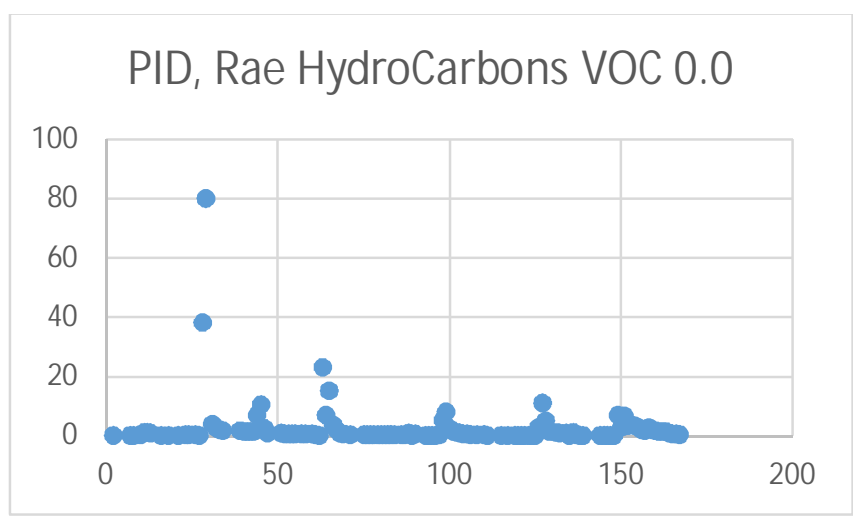

Figure 6. Peak results, sensor; RAE MultiRae 3000, VOC

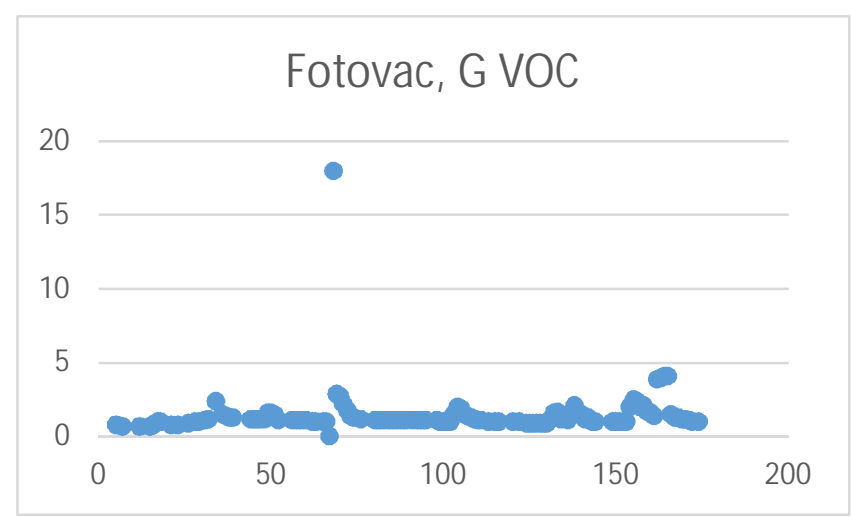

Figure 7. Peak results, sensor: FotoVac, VOC

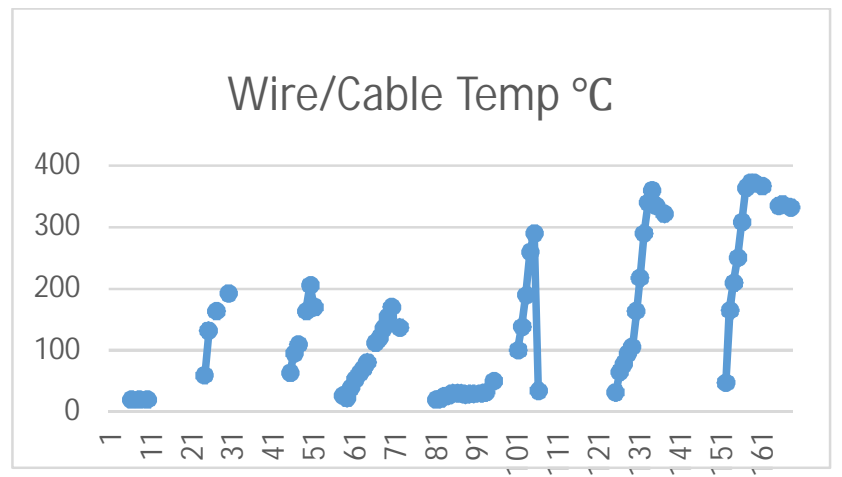

Figure 8. Peak results, cable, Temperature \& Time units

\section{Discussion}

With fully autonomous mines, meaning no miners being present, the need for detecting changes in production that may cause a stop needs to be faster than today. This requires solutions which support smart inspections and early discovery of changes before the situation develops into a dangerous state.

To resolve these issues, this paper explored the possibility with sensors for detecting in an early state, possible fire situation on mining vehicles

A compilation of the results from the sensor tests have been presented including possible influence of the investigated parameters. Furthermore, a discussion of possible diagnostic as for detection of fires risk will now follow. The focus is to determine suitable sensors to be monitored for minimizing the number of fires caused by vehicles in the Swedish mines.

\subsection{Future tests and research plans}

Concluding, the authors realize that one of the essential parts for succeeding will require a system where the data from the sensors can be gathered and analyzed. With diagnostic of only one sensor a simple setpoint with predefined minimum and maximum values could be used. Warning and alarm could be triggered as for shown in an operation system available at the mining site. In the near future, the plan is to 
make a proof of concept test where sensors will be installed on an Epiroc vehicle that is running in one of the underground mines in Sweden. The goal is to connect the sensor to the vehicle's communication system which in turn communicates via the mines IS/IT solution to the safety system, Mobilaris. This system can today show where miners, machines and vehicle are located on a 3D picture of the underground mine shafts. Adding to this view information of e.g. gas levels from the vehicle a dangerous state might be able to be detected in due time.

The final aim is to study the possibility with artificial intelligence, machine and deep learning. Continuously gathering signals from a mix of gas sensors on a mining vehicle and correlate these with all other data being gathered, we believe root cause analyzes will give answers to why e.g. a fire started.

Further, we propose that future studies focus on the possibility of utilizing smart sensors combined with edge and fog computing. Investigating the possibility to move some critical analytics to smart sensors on the machine rather than having the signals to go through a cloud and thereby improving the communication speed. We believe this would e.g. detect fire hazards much faster and contribute to a safer mining vehicle.

\section{Conclusions}

Some of the future mining production is predicted to develop into fully autonomous mining processes. In such operation, safety and security will be important aspects. To be able and catch early changes in production on a mining vehicle, the tests shows that a mix of sensors is recommended to be installed (Figure 9). From those, signals can be gathered 24/7 as for monitoring of different values e.g. like:

- volatile organic carbons, VOC

- temperature

- other gases like methane

- oil mist

- tire pressure

- motor temperature

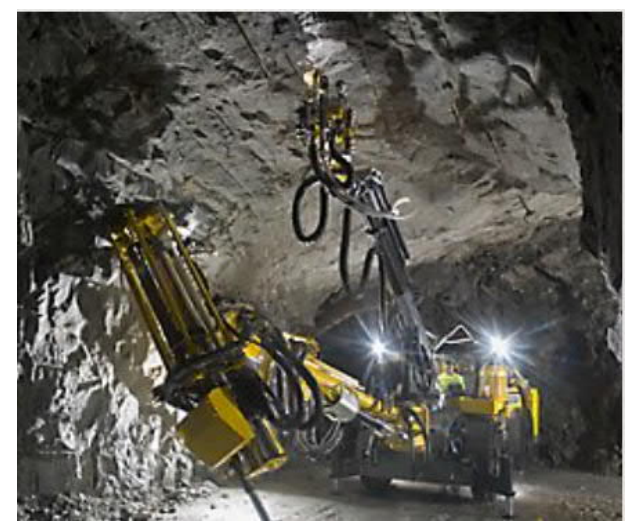

\section{Acknowledgement}

The Swedish Innovation Agency, Vinnova, RISE, Swedish Research Institute in Borås, Epiroc, $\mathrm{ABB}$ and Mälardalens University for their devoted support. Specially thanks to RISE for the great opportunity to run the fire tests in their fire lab facilities.

\section{References}

A Saeter Bøe and N. K. Reitan. Full scale fire test of electrical vehicle, RISE Fire Research, Trondheim, Norway. In Proceed ings from 5 th International Conference Fire in Vehicles FIVE 2018.

H Ingasson, Y. Zehn Li, and A. Lönnermark. Tunnel fire dynamics, Springer, 2015.

A Ahlberg Tidblad. Regulatory outlook on electric vehicle safety, Volvo Car Group, Gothenburg, Sweden. In Proceedings from 5 th International Conference Fire in Vehicles - FIVE 2018.

F Larsson, P. Andersson, and B-E. Mellander. Gas and fire risks with Li-Ion batteries in electrified vehicles. In Proceeding srom 5 th International Conference Fire in Vehicles - FIVE 2018.

N Surendranath Reddy, Srinivasa Saketh M and Sourav Dhar, Review of Sensor Technology for Mine Safety Monitoring Systems: A Holistic Approach, 2016 IEEE First International Conference Control Measurement and Instrumentation.

R Hansen. Design fires in underground hard rock mines, "School of Sustainable Development of Society and Technology, Mälardalens University, Licentiate Thesis 127, Västerås, Sweden, 2011.

R Hansen. Fire statistic from the mining industry in New South Wales, Queensland and Western Australia, "The University of Queensland. DOI: 10.131340/RG.2.2.22666.77767, Australia, 2018.

$\mathrm{O}$ Willstrand. Fire risk management - Best approach to prevent vehicle fires, RISE Research Institutes of Sweden, Fire Research, Borås, Sweden. In Proceedings from 5 th International Conference Fire in Vehicles - FIVE 2018.

$\mathrm{R}$ Hansen. Study of heat release rates of mining vehicles in underground hard rock mines, Mälardalens University Press Dissertation No. 178, Västerås, Sweden, 2015.

A Beard and R. Carvel. Handbook of tunnel fire safety, second edition, 2005.

R Hansen. Investigation on fire causes and fire behavior: Vehicle fires in underground mines in Sweden 1998-2010, Mälardalens University, Västerås, Sweden, 2013.

Natural Resources Canada. Benchmarking the energy consumption of Canadian underground bulk mines. Ref. 2005.

Årsrapport från GRAMKO:s brandskyddskommitté 2012 (in Swedish), SveMin, 2013. GRAMKO annual report.

Figure 9. Underground Mining Vehicle 